\title{
Machinability Study of Steels in Precision Orthogonal Cutting
}

\author{
Leonardo Roberto Silva ${ }^{\mathrm{a} *}$, Alexandre Mendes Abrão ${ }^{\mathrm{b}}$, Paulo Faria $^{\mathrm{c}}$, João Paulo Davim $^{\mathrm{d}}$
}

\author{
${ }^{a}$ Department of Materials Engineering, Federal Center for Technological Education of Minas Gerais - CEFET/MG, \\ Av. Amazonas, 5253, Nova Suíça, CEP 30480-000, Belo Horizonte, MG, Brazil \\ ${ }^{\mathrm{b}}$ Department of Mechanical Engineering, University of Minas Gerais - UFMG, Av. Antônio Carlos, 6627, \\ Pampulha, CEP 31270-901, Belo Horizonte, MG, Brazil \\ 'Department of Production Engineering, University of Minas Gerais - UFMG, Av. Antônio Carlos, 6627, \\ Pampulha, CEP 31270-901, Belo Horizonte, MG, Brazil \\ ${ }^{\mathrm{d}}$ Department of Mechanical Engineering, University of Aveiro - UA, \\ Campus Santiago, 3810-193, Aveiro, Portugal
}

Received: February 26, 2012; Revised: April 27, 2012

\begin{abstract}
The miniaturization of components and systems is advancing steadily in many areas of engineering. Consequently, micro-machining is becoming an important manufacture technology due to the increasing demand for miniaturized products in recent years. Precision machining aims the production of advanced components with high dimensional accuracy and acceptable surface integrity. This work presents an experimental study based on Merchant and Lee \& Shaffer theories applied to precision radial turning of AISI D2 cold work tool and AISI 1045 medium carbon steels with uncoated carbide tools ISO grade $\mathrm{K} 15$. The aim of this study is to evaluate the influence of feed rate on chip compression ratio ( $R$ ), chip deformation $(\varepsilon)$, friction angle $(\rho)$, shear angle $(\phi)$, normal stress $(\sigma)$ and shear stress $(\tau)$ for both work materials. The results indicated that the shear angle decreased and chip deformation increased as the chip compression ratio was elevated without significant differences between both materials. Additionally, higher cutting and thrust forces and normal and shear stresses were observed for the tool steel. Finally, the Lee \& Shaffer model gave shear plane angle values closer to the experimental data.
\end{abstract}

Keywords: orthogonal cutting, precision turning, merchant model, Lee \& Shaffer model, AISI D2 steel, AISI 1045 steel

\section{Introduction}

Micro-machining is becoming an important manufacturing technology due to the increasing demand for miniaturized products in recent years. This is mainly driven by the needs for: greater reduction in size and weight; higher energy efficiency and higher portability in commercial and non-commercial applications. The value of many products can be substantially increased as their size and weight are reduced. The last decade has shown an ever-increasing interest in higher precision and miniaturization in a wide range of manufacturing activities. Many industrial branches require micro-components, for instance, telecommunication, biomedical and micro-intelligent technology. Micromachining by shearing is capable of producing high dimensional and geometric accuracy, surface finish quality and sub-surface integrity at reasonably low costs. Thus, it should be the first choice amongst various manufacturing processes. Furthermore, conventional machining processes such as turning, milling and grinding have already been well established ${ }^{1-4}$. On the other hand, as the feed rate and depth of cut are reduced, special attention must be paid to the cutting edge preparation, otherwise the chip will not be generated owing to the side flow effect.

Most of the experimental research concerning micromachining has been conducted on either conventional

*e-mail: 1rsilva@deii.cefetmg.br precision machine tools or prototype machine tools built by researchers. Conventional machine tools used to precision machining have improved considerably with regard to motion accuracy, stiffness and capability. In general, micromachining is performed on precision machine tools with power and dimensions typical of conventional machines, however, the required power and the work size are much smaller when micro-machining ${ }^{5-6}$.

Micro-cutting of steel has recently caught research interest with the advent of miniaturized systems using a variety of materials, especially for biomedical applications. The material and geometry of micro-tools are important factors to be considered. The feature size is limited by the size of the micro-tools and tungsten carbide tools are generally suitable for machining a variety of engineering materials. The size and quality of micro-products depends on the properties of the machine tools used to produce them, including their accuracy and their dynamic performance ${ }^{6}$.

The principal difference between conventional and micro-machining resides in the cutting mechanism. In general, the cutting mechanism in conventional machining is mainly shearing of the material ahead of the tool wedge, resulting in chip formation. In contrast, micro-machining relies on more complicated mechanisms depending on the degree of the size effect ${ }^{5}$. In micro-machining the so called 
"size effect" is identified as critical in defining process performance. Size effects refers to the phenomenon whereby the reduction of the undeformed chip thickness to levels below the cutting edge radius, or gain size of the workpiece material begins to influence workpiece material deformation mechanisms, chip formation and flow ${ }^{7}$.

Davim et al. ${ }^{8}$ compared finite element model (FEM) simulations with experimental and analytical findings concerning precision radial turning of AISI D2 steel using uncoated carbide cutting tools. FEM machining simulation employs a Lagrangian finite element based machining model applied to predict cutting and thrust forces, cutting temperature and plastic strain distribution. The results show that the difference between the experimental and simulated cutting force was approximately $20 \%$ and was not drastically affected by the friction coefficient employed in the FEM model.

The model proposed by Merchant ${ }^{9}$ has been extensively applied to metal cutting since its advent owing to the fact that it provides quite reliable data with regard to the plastic deformation in the primary shear plane, thus allowing the prediction of the imposed forces and stresses.

The chip compression ratio $\left(\mathrm{R}_{\mathrm{c}}\right)$, as defined by Merchant ${ }^{9-10}$, is given by:

$R_{c}=\frac{t}{t}$

Where $t^{\prime}$ is the chip thickness and $\mathrm{t}$ is the undeformed chip thickness, i.e., $t=f$ for orthogonal cutting.

The shear plane angle $(\phi)$ can be determined experimentally from the chip compression ratio ${ }^{9,11-13}$ using Equation 2:

$\phi=\arctan \frac{\cos \gamma}{R_{c}-\sin \gamma}$

Where $\gamma$ is the rake angle.

From the cutting forces and the shear plane angle, the shear and normal stresses along the shear plane can be calculated $^{9,11-13}$ using, respectively, Equations 3 and 4:

$\tau=\left(\frac{F_{c} \cos \phi-F_{t} \sin \phi}{c \cdot t}\right) \sin \phi$

$\sigma=\left(\frac{F_{c} \sin \phi+F_{t} \cos \phi}{c \cdot t}\right) \sin \phi$

Where $F_{c}$ is the cutting force $(\mathrm{N}), \mathrm{F}_{\mathrm{t}}$ is the thrust force $(\mathrm{N})$ and $\mathrm{c}$ is the width of cut $(\mathrm{mm})$. As a result, the chip deformation $(\varepsilon)$ can be obtained from $\mathrm{R}_{\mathrm{c}}$ and $\gamma^{11}$ :
$\varepsilon=\frac{1+R_{c}^{2}-2 R_{c} \sin \gamma}{R_{c} \cos \gamma}$

The shear plane angle $(\phi)$ is the angle at which the shear stress equals the shear strength of the work material, therefore the shear deformation occurs preferably at this angle. Determination of shear angle has been the subject matter of a number of studies. According to Merchant ${ }^{9,11-13}$, it can be calculated by taking the derivative of the shear stress (Equation 3) with respect to $\phi$ and considering its value zero (relative maximum of the function $\tau$ ), see Equation 6 :

$\phi_{M}=\frac{\pi}{4}-\frac{1}{2}(\rho-\gamma)$

Alternatively, Lee \& Shaffer ${ }^{14}$ obtained the shear plane relationship presented in Equation 7 by assuming that the material was an ideal rigid-plastic solid and the shear plane would be located in the direction of maximum shear, the work of separation not being included in this derivation.

$\phi_{L S}=\frac{\pi}{4}-\rho+\gamma$

According to $0^{9,11-13}$, the mean friction angle $(\rho)$ can be estimated using the cutting and thrust forces $\left(\mathrm{F}_{\mathrm{c}}\right.$ and $\left.\mathrm{F}_{\mathrm{t}}\right)$ and the rake angle $(\gamma)$ as indicated in Equation 8:

$\rho=\arctan \mu=\frac{F_{c} \sin \gamma+F_{t} \cos \gamma}{F_{c} \cos \gamma-F_{t} \sin \gamma}$

The aim of this work is to compare the results from the models proposed by both Merchant ${ }^{9}$ and Lee \& Shaffer ${ }^{14}$ with experimental data when precision radial turning AISI D2 cold work tool steel and AISI 1045 medium carbon steel using grade K15 uncoated carbide inserts without chip breaker at various feed rate values under dry cutting.

\section{Experimental Procedure}

Bars of AISI D2 cold work die steel and AISI 1045 medium carbon steel were used as work materials. Table 1 presents the chemical compositions and mechanical properties of these materials.

Radial turning tests were carried out using ISO grade K15 uncoated cemented carbide inserts (Sandvik Coromant geometry N151.2-540-40-3B and grade H13A). The experimental setup is shown in Figure 1. The inserts were mounted on a tool holder coded LF 151.22-2020-40, thus resulting in the following angles: clearance angle $\alpha=0^{\circ}$, cutting edge inclination angle $\lambda=0^{\circ}$ and rake angle $\gamma=0^{\circ}$. A fresh cutting edge was used for each test, therefore, tool wear was considered negligible throughout the

Table 1. Chemical composition in \% weight and mechanical properties of work materials.

\begin{tabular}{lcccccccccc}
\hline $\begin{array}{l}\text { Work } \\
\text { material }\end{array}$ & C & Mn & Si & Cr & Mo & V & $\begin{array}{c}\text { Tensile strength } \\
(\mathbf{M P a})\end{array}$ & $\begin{array}{c}\text { Yield strength } \\
(\mathbf{M P a})\end{array}$ & $\begin{array}{c}\text { Elongation } \\
(\%)\end{array}$ & $\begin{array}{c}\text { Hardness } \\
(\mathbf{H B})\end{array}$ \\
\hline $\begin{array}{l}\text { AISI D2 } \\
\text { Steel }\end{array}$ & 1.55 & 0.50 & 0.30 & 12.0 & 0.80 & 0.90 & $710-1260$ & 2320 & $\geq 16$ & 260 \\
\hline $\begin{array}{l}\text { AISI 1045 } \\
\text { Steel }\end{array}$ & 0.45 & 0.65 & 0.25 & - & - & - & $600-720$ & $\geq 360$ & 218 & 205 \\
\hline
\end{tabular}


experimental program. An average of three measurements was taken for making graphics and Table 2 and 3.

Dry radial turning experiments were conducted on a Kingsbury MHP $50 \mathrm{CNC}$ lathe with $18 \mathrm{~kW}$ power and maximum spindle speed of $4500 \mathrm{rpm}$. Constant cutting speed $\left(\mathrm{v}_{\mathrm{c}}\right)$ of $70 \mathrm{~m} / \mathrm{min}$ and width of cut (c) of $2.7 \mathrm{~mm}$ values were used, while the following feed rates (f) were tested: 10, 20, 40 and $80 \mu \mathrm{m} \cdot \mathrm{rev}^{-1}$.

The tool holder was mounted on a Kistler ${ }^{\circledR}$ piezoelectric dynamometer model 9121 with a load amplifier connected to a computer which was used for the acquisition of the cutting $\left(\mathrm{F}_{\mathrm{c}}\right)$ and thrust $\left(\mathrm{F}_{\mathrm{t}}\right)$ forces, as shown in Figure 2. Kistler Dynoware $^{\circledR}$ software was used for data acquisition. The equipment, provided with a static and dynamic calibration record, presents a working range from 0 to $600 \mathrm{~N}$ to $\mathrm{F}_{\mathrm{c}}$ and from 0 to $300 \mathrm{~N}$ to $\mathrm{F}_{\mathrm{t}}$. Moreover, the above mentioned dynamometer possesses a natural frequency of $1 \mathrm{kHz}$,

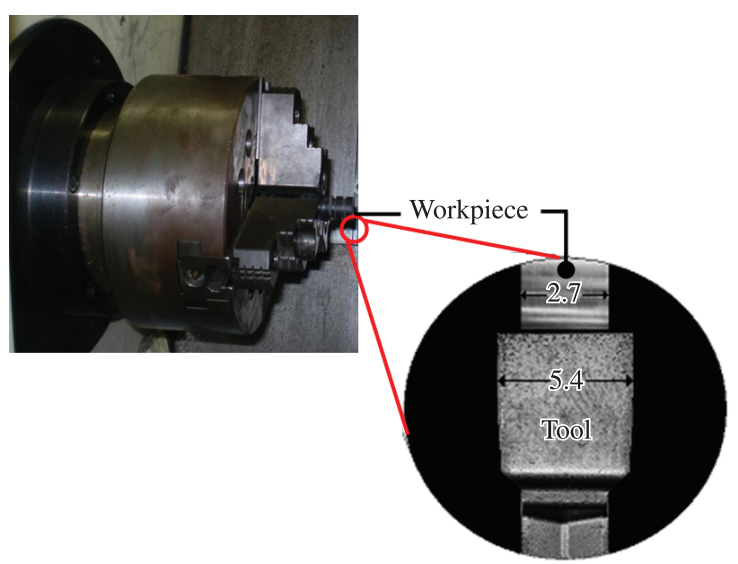

Figure 1. Workpiece and cutting tool used in the experimental work. linearity lower than $1 \%$ and sensitivity of $-3,8 \mathrm{pC} . \mathrm{N}^{-1}$ for $\mathrm{F}_{\mathrm{c}}$ and $-7,9 \mathrm{pC} . \mathrm{N}^{-1}$ for $\mathrm{F}_{\mathrm{t}}$. Chip thickness ( $\mathrm{t}^{\prime}$ ) measurement was undertaken with a Mitutoyo ${ }^{\circledR}$ digital micrometer (range of 0-25 $\mathrm{mm}$ and resolution of $1 \mu \mathrm{m}$ ).

\section{Results and Discussion}

Using the chip thickness value it is possible to calculate the chip compression ratio $\left(R_{c}\right)$ using Equation 1, the shear plane angle $(\phi)$ through Equation 2 and finally the chip deformation $(\varepsilon)$ using Equation 5. Table 2 gives the values of chip compression ratio, shear plane angle and chip deformation as a function of feed rate when precision radial turning AISI 1045 and AISI D2 steels.

It can be noticed in Figure 3 that the value of the experimental shear plane angle $(\phi)$ decreases as the chip compression ratio $(R)$ increases. The value of chip compression ratio and therefore of the shear plane angle provide an indicative of the amount of plastic deformation at the shear zone, i.e., low $\phi$ values (high $R_{c}$ values) mean large amounts of strain in the shear plane.

Figure 4 presents the influence of the chip compression ratio $\left(R_{c}\right)$ on the chip deformation value $(\varepsilon)$, where it can be seen a smooth increase in $\varepsilon$ as $R_{c}$ is elevated, irrespectively of the work material. The cutting and thrust force values recorded at distinct feed rate values $\left(10,20,40\right.$ and $\left.80 \mu \mathrm{m} \cdot \mathrm{rev}^{-1}\right)$ are presented in Figure 5. It can be noticed that when machining AISI D2 steel, the cutting and thrust forces present higher values owing to its superior hardness and tensile strength (see Table 1). The cutting force values increase drastically with feed rate and the thrust force component increases slightly. In addition to that, the forces recorded when cutting the tool steel present less scatter compared with the carbon steel.

Table 2. Values of chip compression ratio $\left(\mathrm{R}_{\mathrm{c}}\right)$, experimental shear plane angle $(\phi)$ and chip deformation $(\varepsilon)$ as functions of feed rate when precision turning of AISI 1045 and AISI D2 steels.

\begin{tabular}{|c|c|c|c|c|c|c|c|c|c|}
\hline \multirow[t]{2}{*}{$\begin{array}{c}\text { Feed rate (f) } \\
{\left[\mu \mathrm{m} . \mathrm{rev}^{-1}\right]}\end{array}$} & \multirow[t]{2}{*}{$\begin{array}{l}\text { Undeformed chip } \\
\text { thickness }(\mathrm{t}) \\
{[\mu \mathrm{m}]}\end{array}$} & \multicolumn{2}{|c|}{$\begin{array}{c}\text { Chip thickness (t') } \\
{[\mu \mathrm{m}]}\end{array}$} & \multicolumn{2}{|c|}{$\begin{array}{l}\text { Chip compression } \\
\text { ratio }\left(\mathbf{R}_{\mathrm{c}}\right)\end{array}$} & \multicolumn{2}{|c|}{$\begin{array}{c}\text { Experimental shear plane } \\
\text { angle }(\phi) \\
{\left[{ }^{\circ}\right]} \\
\end{array}$} & \multicolumn{2}{|c|}{$\begin{array}{c}\text { Chip } \\
\text { deformation } \\
(\varepsilon) \\
\end{array}$} \\
\hline & & $\begin{array}{l}\text { AISI } \\
1045\end{array}$ & $\begin{array}{c}\text { AISI } \\
\text { D2 }\end{array}$ & $\begin{array}{l}\text { AISI } \\
1045\end{array}$ & $\begin{array}{c}\text { AISI } \\
\text { D2 }\end{array}$ & $\begin{array}{l}\text { AISI } \\
1045\end{array}$ & $\begin{array}{c}\text { AISI } \\
\text { D2 }\end{array}$ & $\begin{array}{l}\text { AISI } \\
1045\end{array}$ & $\begin{array}{c}\text { AISI } \\
\text { D2 }\end{array}$ \\
\hline 10 & 10 & 43.3 & 46.7 & 4.33 & 4.67 & 13.00 & 12.09 & 4.56 & 4.88 \\
\hline 20 & 20 & 65 & 85 & 3.25 & 4.25 & 17.10 & 13.24 & 3.56 & 4.49 \\
\hline 40 & 40 & 150 & 138.3 & 3.75 & 3.46 & 14.93 & 16.12 & 4.02 & 3.75 \\
\hline 80 & 80 & 308.3 & 246.7 & 3.85 & 3.08 & 14.56 & 17.99 & 4.11 & 3.40 \\
\hline
\end{tabular}

Table 3. Values of the friction angle $(\rho)$, experimental shear plane angle $(\phi)$ and Merchant $\left(\phi_{\mathrm{M}}\right)$ and Lee \& Shaffer $\left(\phi_{\mathrm{LS}}\right)$ shear plane angle as functions of feed rate.

\begin{tabular}{|c|c|c|c|c|c|c|c|c|}
\hline \multirow[t]{3}{*}{$\begin{array}{c}\text { Feed rate } \\
\text { (f) }\left[\mu \mathrm{m} \cdot \mathrm{rev}^{-1}\right]\end{array}$} & \multicolumn{2}{|c|}{$\begin{array}{l}\text { Friction angle } \\
(\rho)\left[{ }^{\circ}\right]\end{array}$} & \multicolumn{2}{|c|}{$\begin{array}{c}\text { Experimental shear plane } \\
\text { angle }(\phi)\left[^{\circ}\right]\end{array}$} & \multicolumn{2}{|c|}{$\begin{array}{c}\text { Merchant shear } \\
\text { plane angle }\left(\phi_{M}\right)\left[^{\circ}\right]\end{array}$} & \multicolumn{2}{|c|}{$\begin{array}{l}\text { Lee \& Shaffer shear } \\
\text { plane angle }\left(\phi_{\mathrm{LS}}\right)\left[^{\circ}\right]\end{array}$} \\
\hline & AISI & AISI & AISI & AISI & AISI & AISI & AISI & AISI \\
\hline & 1045 & D2 & 1045 & D2 & 1045 & D2 & 1045 & D2 \\
\hline 10 & 16.03 & 22.32 & 13.00 & 12.09 & 36.99 & 33.84 & 28.97 & 22.68 \\
\hline 20 & 16.77 & 22.53 & 17.10 & 13.24 & 36.62 & 33.74 & 28.23 & 22.47 \\
\hline 40 & 18.96 & 22.12 & 14.93 & 16.12 & 35.52 & 33.94 & 26.04 & 22.88 \\
\hline 80 & 23.18 & 21.48 & 14.56 & 17.99 & 33.41 & 34.26 & 21.82 & 23.52 \\
\hline
\end{tabular}



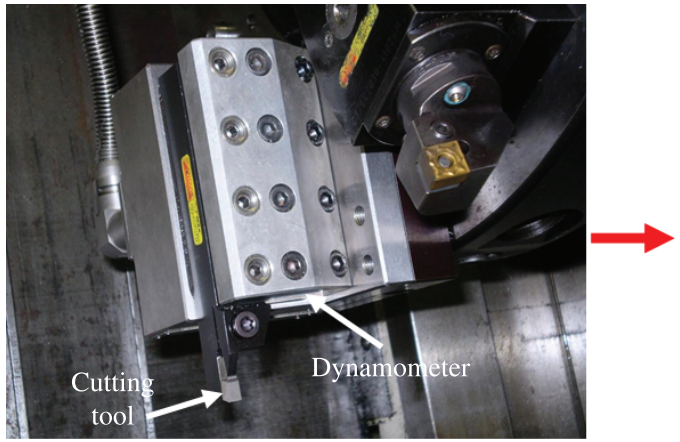

Figure 2. Radial machining forces measurement setup.

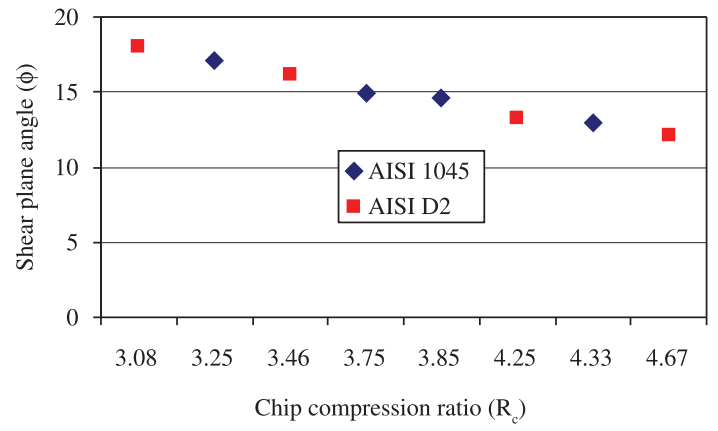

Figure 3. Experimental shear plane angle versus chip compression ratio.

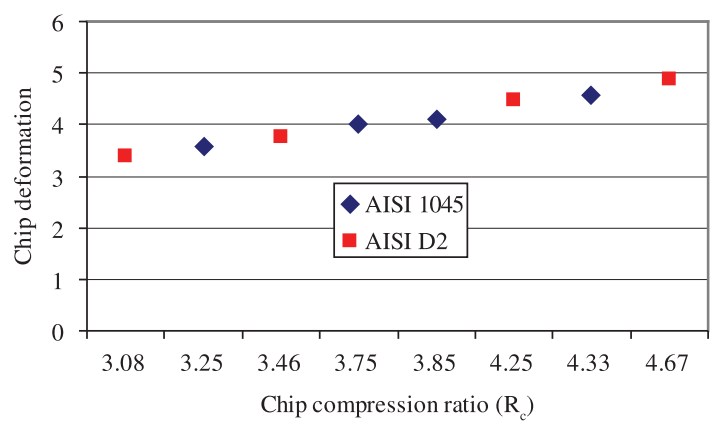

Figure 4. Chip deformation versus chip compression ratio.

Figure 6 presents the evolution of the average cutting and thrust forces as a function of feed rate when turning both materials, where it can be observed that the cutting and thrust forces increases drastically with feed rate. Nevertheless, the difference between the forces recorded when turning die steel and carbon steel tend to decrease as feed rate is elevated.

From Equation 6, concerned with Merchant model, it is possible to obtain the value of the shear plane angle $\left(\phi_{M}\right)$ from the friction angle value $(\rho)$ calculated from Equation 8 . This procedure allows a comparison between the experimental values and those derived from both Merchant ${ }^{9}$ and Lee \& Shaffer ${ }^{14}$ models, both analytical models depending on the rake and friction angles. Table 3 presents the results obtained through both methods and Figure 7 compares the values for the shear plane angle $(\phi)$ obtained by the three methods. It can be seen that both materials presented significant difference between experimental and analytical values, possibly due to the low feed rate values used, which provided larger deformation, associated to the fact that both methods do not take work hardening into account.

The values predicted by Lee $\&$ Shaffer ${ }^{14}$ tend to be closer to the experimental data, nevertheless, differences are to be expected owing to the fact that elastic strain and the influence of temperature are neglected. In addition to that, according to Lee \& Shaffer ${ }^{14}$ model the shear stress should equal the normal stress on the shear plane, however this is not observed. According to Bil et al. ${ }^{15}$, Lee \& Shaffer ${ }^{14}$ model, which is relatively simpler than the others, gives good predictions. These authors found simulated similar to with those given by Lee \& Shaffer ${ }^{14}$ model, especially for a rake angle of $20^{\circ}$. Furthermore, the shear plane angle calculated according to Merchant model considers the shear stress value constant, which may not be accurate. According to Childs et al. ${ }^{16}$, although Merchant ${ }^{9}$ and Lee \& Shaffer ${ }^{14}$ models correctly show that the shear plane angle increases as the rake angle is elevated and the friction angle is reduced, this universal relationship is not supported experimentally.

Shaw ${ }^{10}$ regards Lee \& Shaffer ${ }^{14}$ model as the best starting point due to the fact that it considers the least objectionable assumptions. In spite of that, correction factors encompassing the presence of built up edge, the size of the secondary shear zone, chip curl, tool wear and strain hardening should be incorporated in the model.

Through Equations 3 and 4 it is possible to obtain the normal stress $(\sigma \pi)$ and the shear stress $(\tau \pi)$ values. Figures 8 and 9 show, respectively, the evolution of the normal stress $(\sigma \pi)$ and the shear stress $(\tau \pi)$ values as feed rate increases. It can be observed that the normal stress $(\sigma \pi)$ is always lower than the shear stress $(\tau \pi)$, both stresses tending to reduce as the feed rate is elevated. Moreover, higher normal and shear stress values are obtained during the machining of AISI D2 steel, in spite of the reduction in the difference recorded for both materials as feed rate is elevated. This can be explained by the higher experimental shear plane 


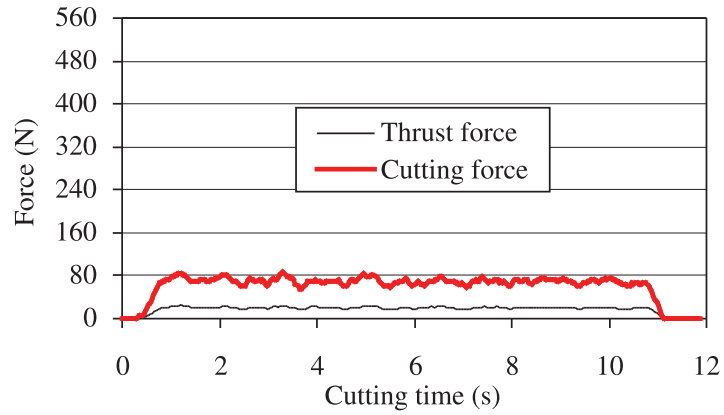

(a) AISI 1045 steel $(\mathrm{f}=10 \mu \mathrm{m} / \mathrm{rev})$

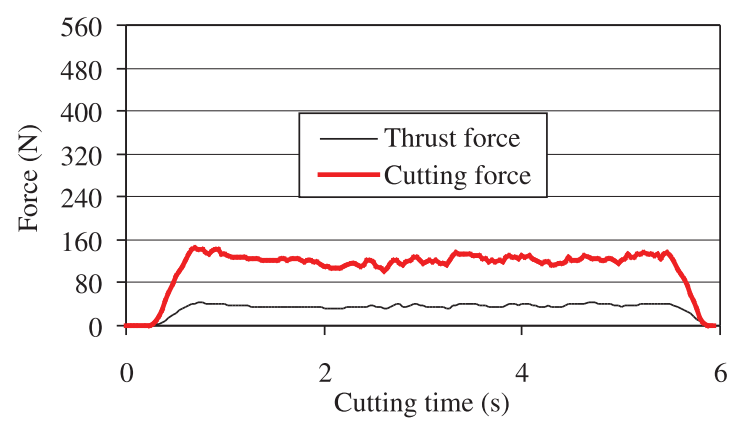

(b) AISI 1045 steel ( $f=20 \mu \mathrm{m} / \mathrm{rev}$ )

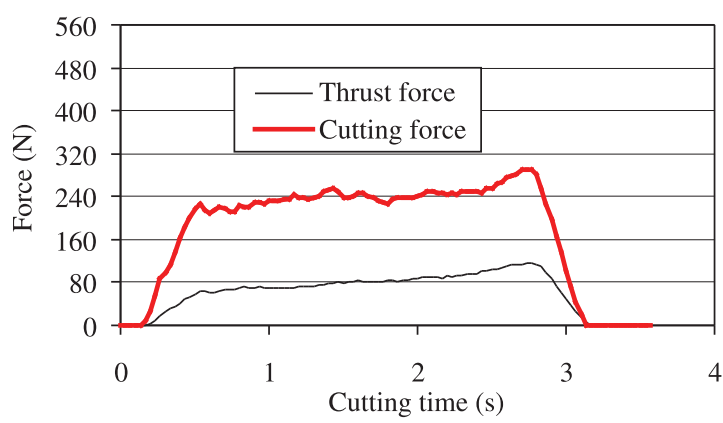

(c) AISI 1045 steel ( $\mathrm{f}=40 \mu \mathrm{m} / \mathrm{rev}$ )

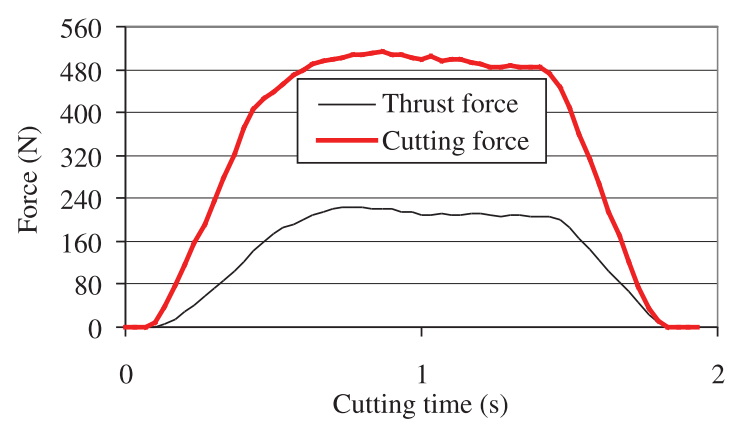

(d) AISI 1045 steel $(\mathrm{f}=80 \mu \mathrm{m} / \mathrm{rev})$

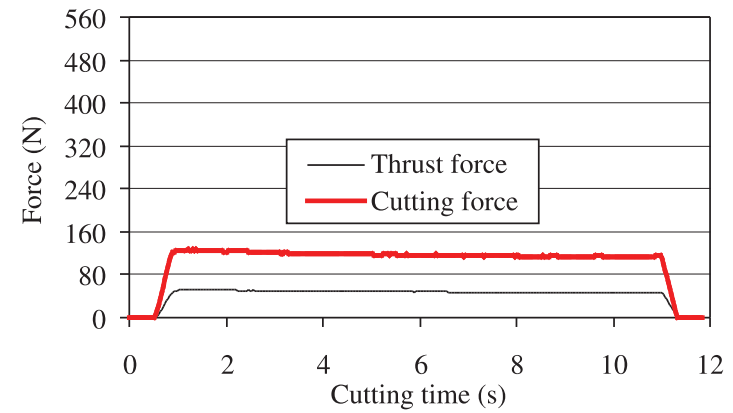

(e) AISI D2 steel ( $\mathrm{f}=10 \mu \mathrm{m} / \mathrm{rev})$

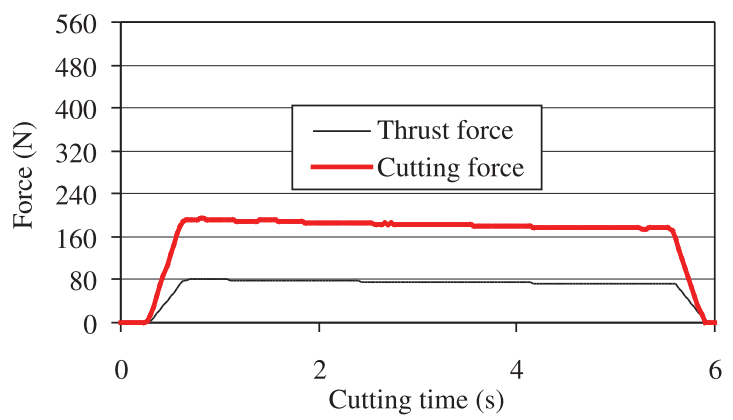

(f) AISI D2 steel (f $=20 \mu \mathrm{m} / \mathrm{rev})$

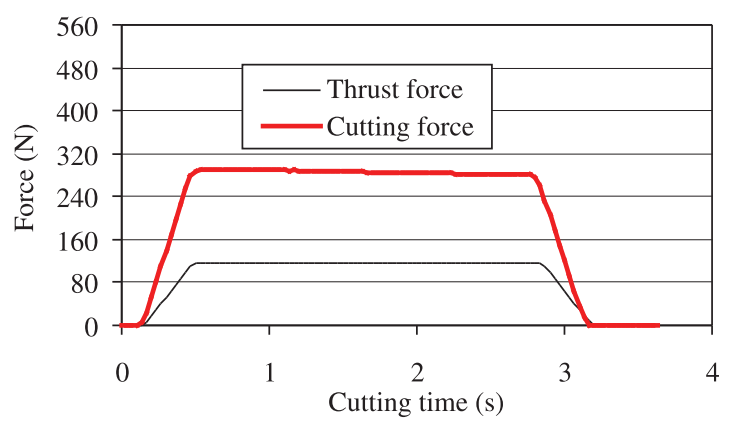

(g) AISI D2 steel (f $=40 \mu \mathrm{m} / \mathrm{rev})$

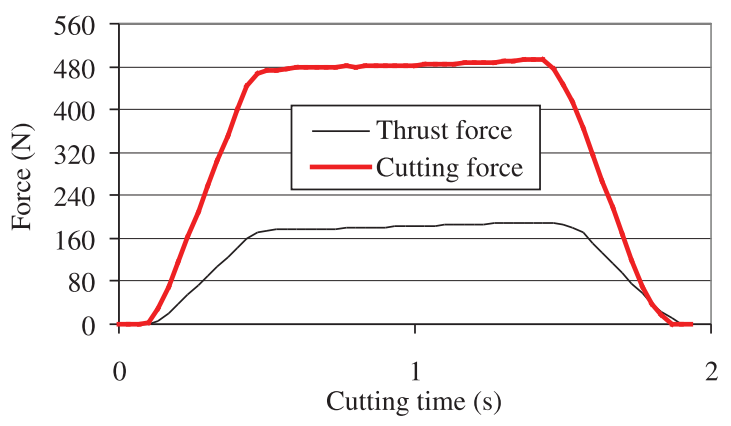

(h) AISI D2 steel ( $\mathrm{f}=80 \mu \mathrm{m} / \mathrm{rev})$

Figure 5. Cutting and thrust forces evolution when cutting of AISI 1045 and AISI D2 steels at $\mathrm{v}_{\mathrm{c}}=70 \mathrm{~m} / \mathrm{min}$ with K15 uncoated cemented carbide tool. 


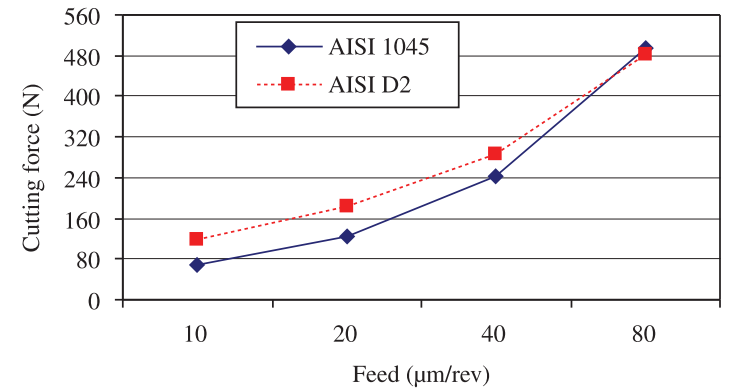

(a) Cutting force

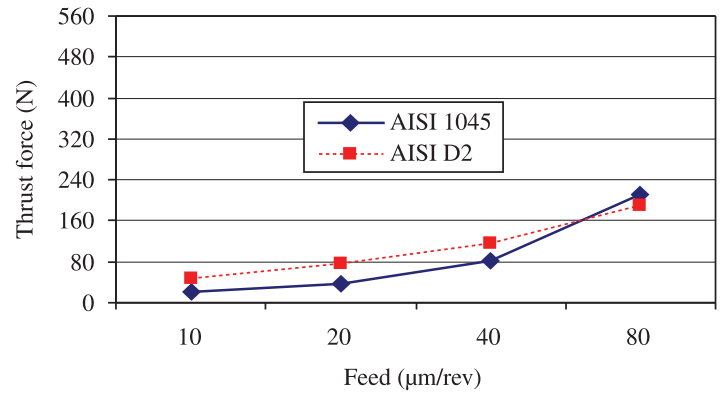

(b) Thrust force

Figure 6. Effect of feed rate on average cutting and thrust forces when machining of AISI 1045 and AISI D2 steels at $\mathrm{v}_{\mathrm{c}}=70 \mathrm{~m} / \mathrm{min}$ with K15 uncoated cemented carbide tool.

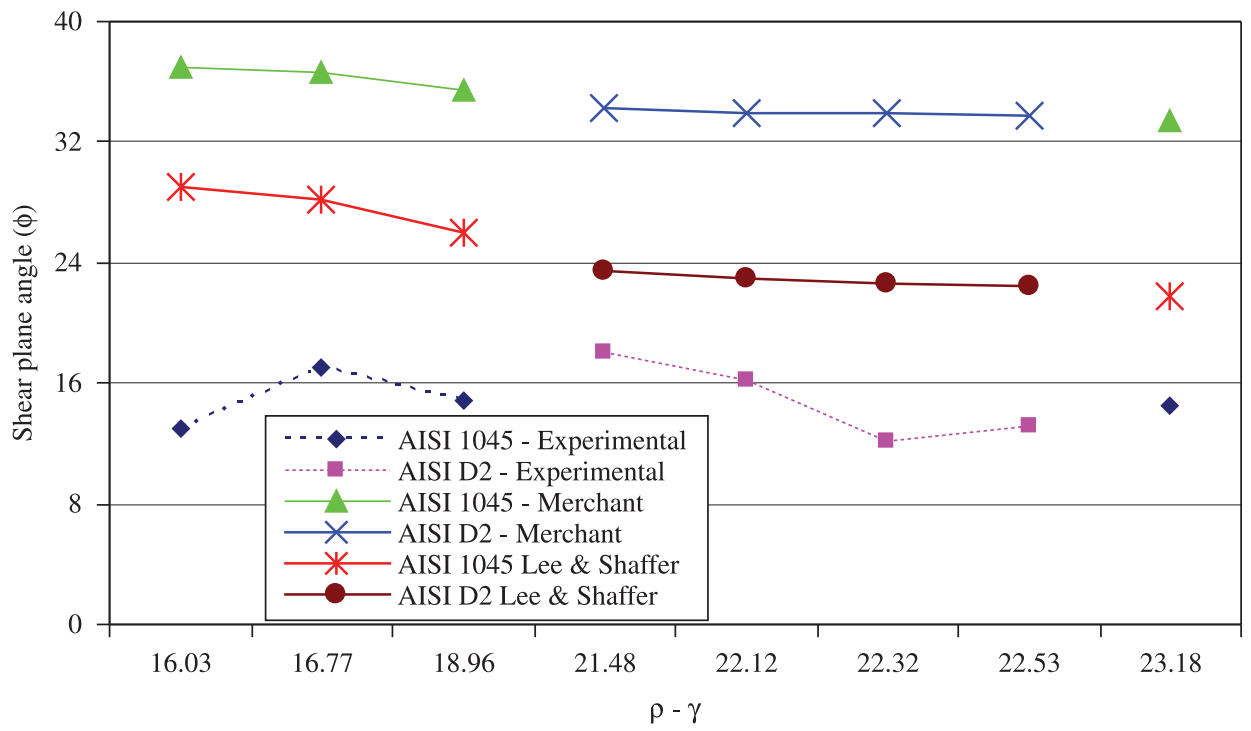

Figure 7. Comparison between Merchant ${ }^{9}$ and Lee \& Shaffer ${ }^{14}$ models and the experimental results: shear plane angles $\left(\phi, \phi M\right.$ and $\left.\phi_{L S}\right)$ versus $(\rho-\gamma)$.

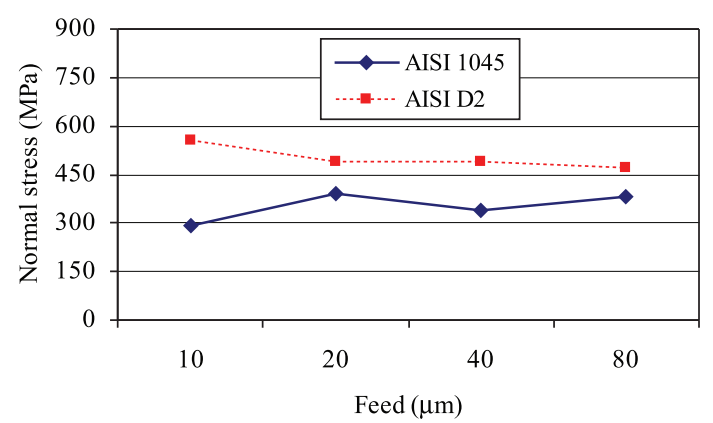

Figure 8. Effect of feed rate on normal stress.

angle values observed for the tool steel at feed rates of 40 and $80 \mu \mathrm{m} \cdot \mathrm{rev}^{-1}$.

Summarizing the above considerations, it can be concluded that each observed cutting model reflects a particular aspect of metal cutting practice, in reality, the cutting conditions may be created where one or another model is valid, but no one model covers the whole variation of cutting conditions.

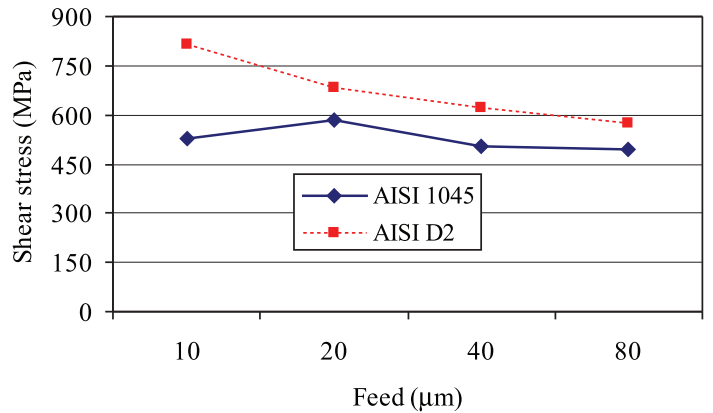

Figure 9. Effect of feed rate on shear stress.

\section{Conclusions}

After precision radial turning of AISI D2 cold work tool steel and AISI 1045 medium carbon steel the following conclusions can be drawn:

- Correlations between the chip compression ratio and shear plane angle or chip deformation were obtained for both materials. The shear angle decreased with 
the chip compression ratio. In contrast, the chip deformation increased with the chip compression ratio.

- The AISI D2 tool steel presented higher values for cutting and thrust forces, and consequently higher normal and shear stresses.

- Comparing the experimental values for the shear plane angle with those provided by Merchant and Lee \& Shaffer models, the latter tended to get closer to the experimental data.

\section{References}

1. Fang FZ and Liu YC. On minimum exit-burr in micro cutting. Journal Micromech Microeng. 2004; 14:984-8. http://dx.doi. org/10.1088/0960-1317/14/7/020

2. Azizur Rahman M, Rahman M, Senthil Kumar A and Lim HS. CNC microturning: an application to miniaturization. International Journal of Machine Tools \& Manufacture. 2005; 45:631-9. http://dx.doi.org/10.1016/j. ijmachtools.2004.10.003

3. Fang FZ, Wu H, Liu XD, Liu YC and Ng ST. Tool geometry study in micromachining. Journal Micromech Microeng. 2003; 13:726-31. http://dx.doi.org/10.1088/0960$1317 / 13 / 5 / 327$

4. Weck M, Fischer S and Vos M. Fabrication of microcomponents using ultraprecision machine tools. Nanotechnology. 1997; 8:145-48. http://dx.doi. org/10.1088/0957-4484/8/3/007

5. Dornfeld D, Min S, Takeuchi Y. Recent Advances in Mechanical Micromachining. Annals CIRP. 2006; 55-2:745-68.

6. Chae J, Park SS and Freiheit T. Investigation of microcutting operations. International Journal of Machine Tools \& Manufacture. 2006; 46:313-32. http://dx.doi.org/10.1016/j. ijmachtools.2005.05.015

7. Mian AJ, Driver N and Mativenga PT. Identification of factors that dominate size effect in micro-machining. International Journal of Machine Tools \& Manufacture. 2011; 51:383-394. http://dx.doi.org/10.1016/j.ijmachtools.2011.01.004

8. Davim JP, Maranhão C, Faria PE, Abrão AM, Rubio JC and Silva LR. Precision radial turning of AISI D2
- Higher shear stress values were obtained in comparison with the normal stress. Both stresses values were reduced as feed rate was elevated.

\section{Acknowledgements}

The authors would like to thank CAPES (Brazil) and FCT (Portugal) for funding this research project.

steel. International Journal of Advanced Manufacturing Technology. 2009; 42:842-49. http://dx.doi.org/10.1007/ s00170-008-1644-9

9. Merchant ME. Mechanics of metal cutting process. I - Orthogonal cutting and type 2 chip. Journal of Applied Physics. 1945; 16:267-75. http://dx.doi.org/10.1063/1.1707586

10. Groover MP. Fundamentals of Modern Manufacturing Materials. Process and Systems, Prentice Hall International Editions;1996. p. 543-63.

11. Shaw MC. Metal Cutting Principles. New York: Oxford Science Publications; 1984. p. 18-46.

12. Boothroyd G and Knight WA. Fundamentals of Machining and Machine Tools. New York: Marcel Dekker; 1989. p. 73-108.

13. Wyeth DJ. An investigation into the mechanics of cutting using data from orthogonally cutting Nylon 66. International Journal of Machine Tools and Manufacture. 2008; 48:896-904. http:// dx.doi.org/10.1016/j.ijmachtools.2007.11.001

14. Lee EH and Shaffer BW. The theory of plasticity applied to a problem of machining. ASME Journal Applied Mechanics. 1951; 18:405-413.

15. Bil H, Kılıc SE and Tekkaya AE. A comparison of orthogonal cutting data from experiments with three different finite element models. International Journal of Machine Tools and Manufacture. 2004; 44:933-44. http://dx.doi.org/10.1016/j. ijmachtools.2004.01.016

16. Childs T, Maekawa K, Obikawa T and Yamane Y. Metal Machining - Theory and Applications. London: Arnold; 2000.

Appendix 1. Notation.

\begin{tabular}{|c|l|l|l|}
\hline $\mathrm{c}$ & Width of cut & $\phi$ & Experimental shear plane angle \\
\hline $\mathrm{f}$ & Feed rate & $\phi_{\mathrm{M}}$ & Merchant shear plane angle \\
\hline $\mathrm{F}_{\mathrm{c}}$ & Cutting force & $\phi_{\mathrm{LS}}$ & Lee \& Shaffer shear plane angle \\
\hline $\mathrm{F}_{\mathrm{t}}$ & Thrust force & $\alpha$ & Clearance angle \\
\hline $\mathrm{t}$ & Undeformed chip thickness & $\gamma$ & Rake angle \\
\hline $\mathrm{t}^{\prime}$ & Chip thickness & $\lambda$ & Cutting edge inclination angle \\
\hline $\mathrm{R}_{\mathrm{c}}$ & Chip compression ratio & $\rho$ & Friction angle \\
\hline$\varepsilon$ & Chip deformation & $\sigma_{\pi}$ & Normal stress \\
\hline$\tau_{\pi}$ & Shear stress & & \\
\hline
\end{tabular}

